\title{
CONSTRUCTION OF A DETECTOR OF FATIGUE SYMPTOMS IN CAR DRIVERS
}

\author{
Łukasz DZIUDA ${ }^{1}$, Krzysztof MURAWSKI ${ }^{2}$, Mariusz DZIWOSZ ${ }^{1}$, Mariusz KREJ', Marcin \\ PIOTROWSKI ${ }^{3}$, Paulina BARAN ${ }^{1}$ \\ ${ }^{1}$ Department of Flight Simulator Innovations, Military Institute of Aviation Medicine, Warsaw, Poland \\ ${ }^{2}$ Institute of Teleinformatics and Automatics, Faculty of Cybernetics, Military University of Technology, \\ Warsaw, Poland \\ ${ }^{3}$ Department of Simulator Studies and Aeromedical Training, Military Institute of Aviation Medicine, \\ Warsaw, Poland
}

Source of support: This work was supported by the resources of the National Centre for Research and Development, Poland, within the framework of the Applied Research Programme, Project PBS3/B9/29/2015

Author's address: $Ł$. Dziuda, Military Institute of Aviation Medicine, Krasińskiego 54/56 Street, 01-755 Warsaw, Poland, e-mail: Idziuda@wiml.waw.pl

Abstract: This paper is aimed at presenting the main technical aspects of the video recorder developed to detect fatigue symptoms that appear while driving a car. The principle of operation is based on filming the driver's face illuminated with light in the near-infrared band and detecting changes in the location of the characteristic points on the face, which may indicate fatigue. An off-the-shelf camera was used as an element of the detector, whereas another part were the illuminator and software created in-house. The detector's supporting frame was designed to be made using 3D printing technology. The application areas of the detector include monitoring car drivers and other vehicle operators, e.g. rail vehicles, in the context of drowsiness and fatigue during driving.

Keywords: video cameras, car drivers, drowsiness, fatigue symptoms, infrared illuminators, optical sensors, traffic safety

Figures 6 • References: 35 • Full-text PDF: http://www.pjambp.com • Copyright $@ 2018$ Polish Aviation Medicine Society, ul. Krasińskiego 54/56, 01-755 Warsaw, license WIML • Indexation: Index Copernicus, Polish Ministry of Science and Higher Education 


\section{INTRODUCTION}

Fatigue in drivers is a significant issue and real threat to traffic safety. Based on the literature $[14,16,23,27,32]$, driving a car in the state of fatigue is one of the factors significantly increasing the risk of an accident on the road. It is estimated that the probability of participating in an accident of a tired driver may be up to eight times higher than a rested driver [3].

In order to increase the level of driver's safety on the road, it is important to detect psychophysiological symptoms indicating increasing weariness, drowsiness and fatigue while driving a car early enough. The literature lists occulographic parameters and facial mimic-associated indicators, which may reflect an elevated level of fatigue, as follows: the average time of eye fixation $[2,6,9,12,33]$, eye saccadic velocity $[1,4-8]$, percentage of eye closure (PERCLOS) $[15,17,31]$, eye closure duration (ECD), frequency of eye closure (FEC) [11], as well as droopy corners of the mouth [26]. However, other physiological indices of human arousal state in real-world driving, including drowsiness and fatique, are also described in the literature, e.g. heart and brain electrical activity, blood pressure, electrodermal activity and electrical activity generated by muscle fibers [18]. All of them are measured by various systems and devices, which differ, among others, in the way of acquiring physiological signals, the type of construction, the cost of manufacturing, as well as the ergonomics and the degree of comfort of the person being monitored [20-21,29-30,34]. In this paper we present the construction and general technical description of the video sensor designed to capture moving images of the driver's face and identify fatigue signs using software data analysis. The detector itself is a non-invasive measuring device of small (a)

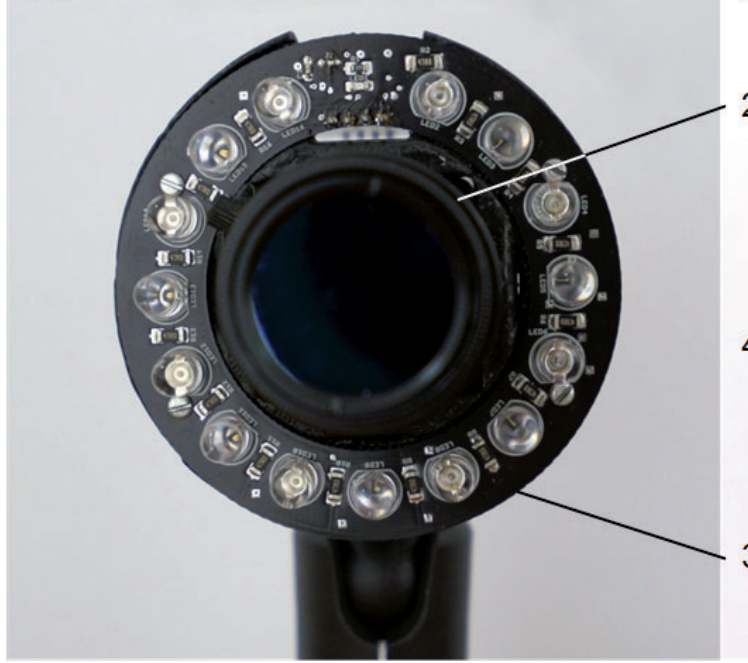

(b)

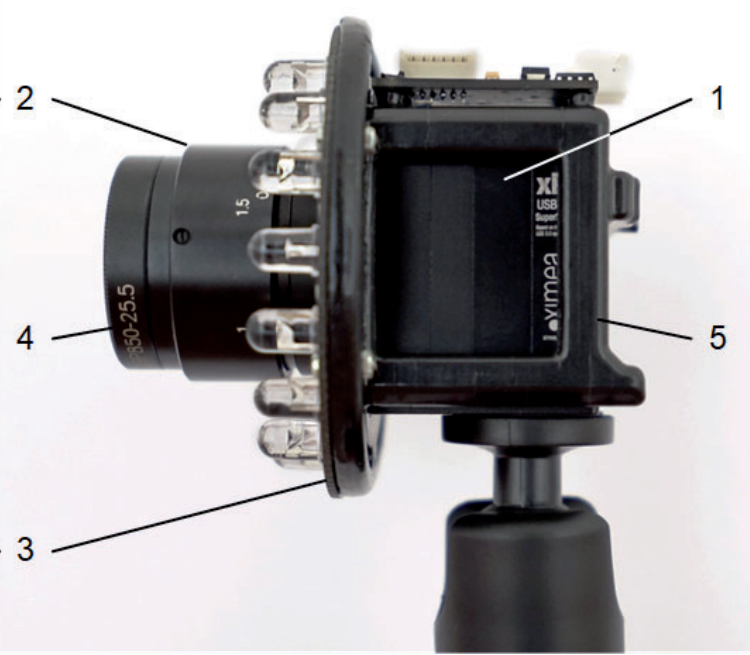

Fig. 1. Main hardware components of the detector: (a) front view and (b) side view.

(a)

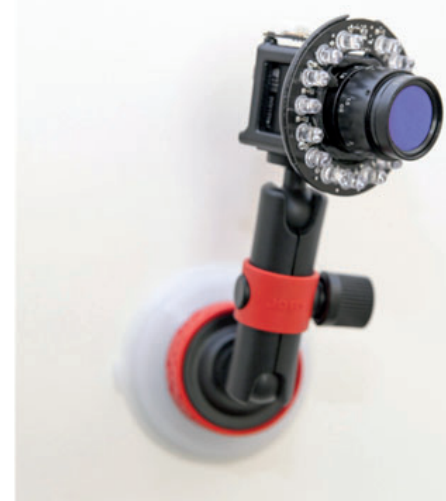

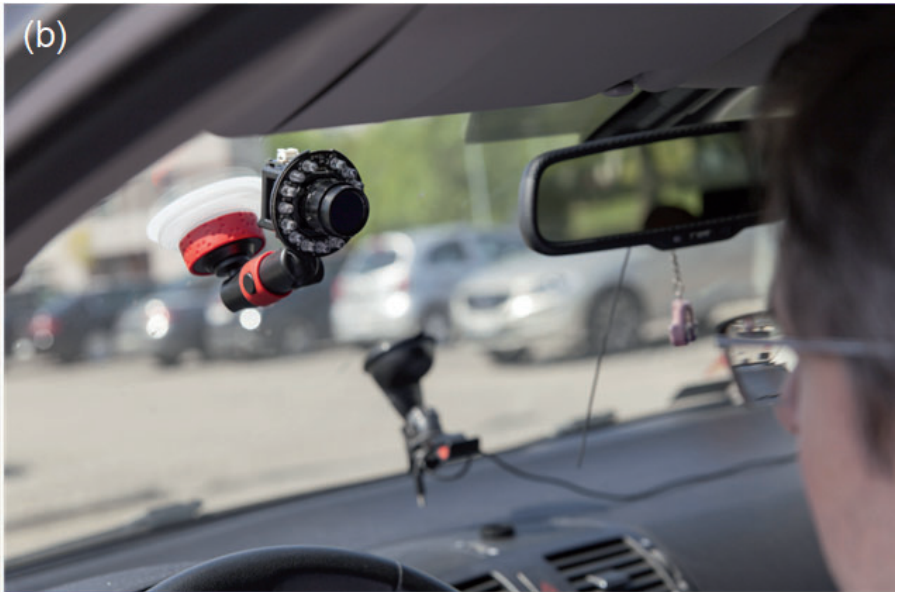

Fig. 2. Detector (a) ready to use and (b) located in the car cabin. 
Dziuda $Ł$. et al. - Construction of a detector ...

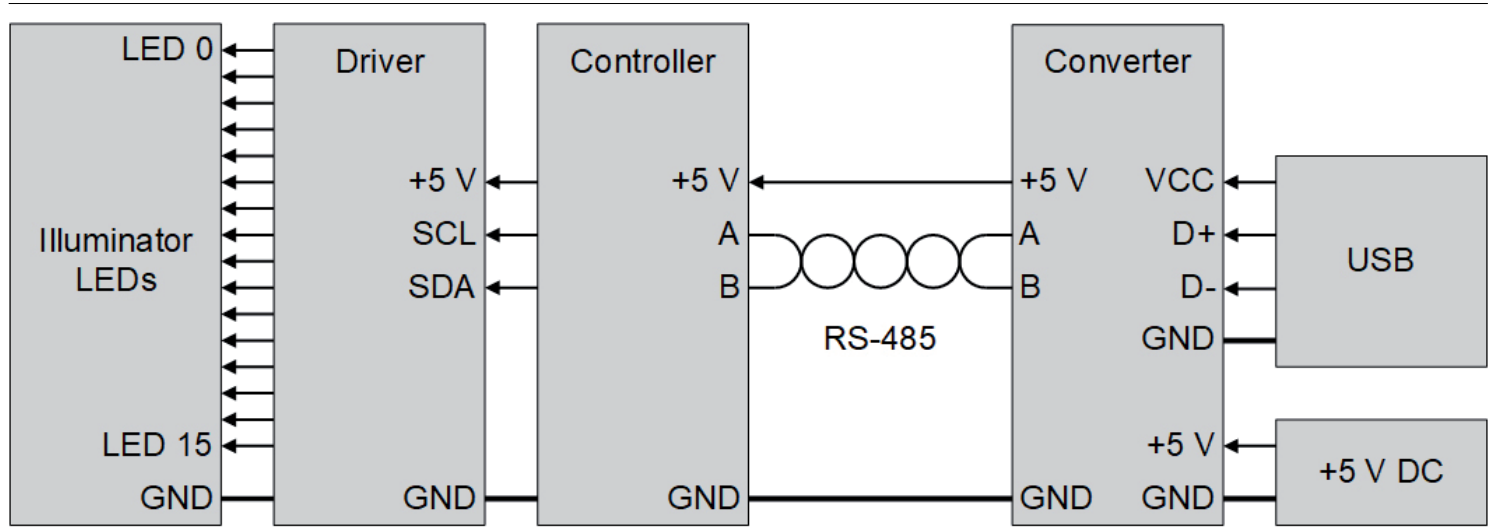

Fig. 3. Schematic diagram of the illuminator structure.

size and relatively inexpensive to build, hence it can be widely used to record fatigue symptoms in vehicle drivers. Nevertheless, the results of the research carried out with this sensor on a group of car drivers will be presented in a separate paper.

\section{GENERAL DESIGN}

The detector consists of hardware and software modules. The hardware module utilizes a commercially available MQ013RG-E2 camera by Ximea (marked ' 1 ' in fig. 1) equipped with $25 \mathrm{HB}$ lens by Tamron (' 2 ' in fig. 1). The camera records images with a resolution of $1280 \times 1024$ pixels at 60 frames per second (fps) using a complementary metaloxide semiconductor (CMOS) near-infrared (NIR) sensor. To enable image recording in places with limited lighting conditions, e.g. in the car cabin, a face illuminator using light in the NIR band was designed (' 3 ' in fig. 1). Additionally, a band-pass filter for the illuminator infrared (IR) light-emitting diodes (LEDs) is applied to the lens (' 4 ' in fig. 1). Both the camera and illuminator were mounted on a supporting frame that was designed as the Standard Template Library (STL) model and made using 3D printing technology (' 5 ' in fig. 1). The supporting frame was mounted on a ball-joint holder with a suction cup to attach the detector to the car window, as shown in fig. 2 .

\section{FACE ILLUMINATOR}

The illuminator was implemented as a clientserver architecture shown schematically in fig. 3. The server was designed using AT89s8253 microcontroller by Microchip Technology, clocked at $11.0592 \mathrm{MHz}$. The microcontroller communicates with the client and controls the operation of the illuminator LEDs. Since the microcontroller is not equipped with the I2C hardware, the transmitter/ receiver of the $\mathrm{I} 2 \mathrm{C}$ bus is achieved in a software way. In order to increase the range of the USB cable between the server and client to tens of meters, the microcontroller is equipped with an UART-to-RS-485 data converter. The A and B lines of the RS-485 interface are connected to the inputs of MAX1487ECSA+ transceiver by Maxim Integrated. By default, the transceiver is configured as the receiver. At the client's request, the microcontroller switches the transceiver to data transfer state. In this case, these are confirmations of the received and executed commands. The received commands affect the states of the $\mathrm{I} 2 \mathrm{C}$ bus lines, which together with the $+5 \mathrm{~V}$ and ground lines are fed to the illuminator controller. The current status of the microcontroller is shown by three indicating LEDs. The controller is also equipped with reset and user buttons. The user button in the adopted software implementation is used to incrementally increase the brightness of the illuminator LEDs. The control of the illuminator LEDs is based on PCA9622DRT driver by NXP Semiconductors, which contains 16 pulse-width modulation (PWM) channels. Each of them can control the LED current up to $100 \mathrm{~mA}$.

The server cooperates with the client via a converter from the RS-485 to UART standard using another MAX1487ECSA+ transceiver, and then from the UART to USB standard using FTDI FT232RL chip. The converter in the host system is recognized as the virtual COM port (VCP). The TxD, RxD, RTS, CTS, CBUSO - CBUS2, CBUS4 and GND lines of the FT232RL chip are used. The TXD line is connected to the DI input of MAX1487ECSA+ transceiver, whereas the RXD signal is connected to its RO output. By connecting the RTS and CTS pins of the FT232RL chip together, the interface is always ready to send and receive data. The CBUS2 and CBUS4 lines are used to control the direction of data transmission on the RS- 485 bus. When the CBUS2 line is in the high state, the data fed to the $D I$ input are delivered to $A$ and $B$ lines. The zero 
state on the CBUS2 line, which is the default state, means blocking the transmitter and entering the data receiving mode. The receiver of the RS 485 bus is controlled by the CBUS4 line. This line is configured as PWREN\#, for which the default state is ' 1 '. The enumeration procedure, after connecting the converter USB connector to the computer socket, changes the state of the CBUS4 line to ' 0 ' and the receiver of the RS 485 bus is ready to receive data. The CBUSO and CBUS1 lines are connected to two indicating LEDs that show the current status, i.e. transmission or receiving mode. Another LED indicates $\mathrm{a}+5 \mathrm{~V}$ power connected to the converter. A photograph of the converter in the form of an USB dongle is shown in fig. 4.

(a)

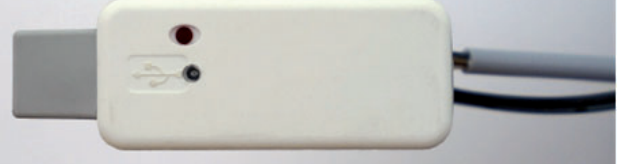

(b)

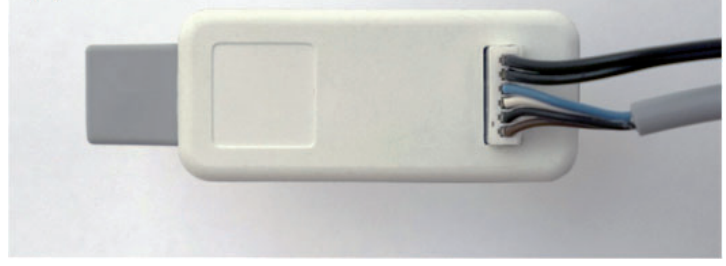

Fig. 4. RS-485-to-USB converter: (a) top view and (b) bottom view.

\section{SOFTWARE}

The computer application allows for detecting the characteristic points on the driver's face in video data captured from the connected camera or archived on the disk. fig. 5 shows the main panel of the application while detecting the characteristic points on the face of a subject. The location of the characteristic points can be visualised in the form of time charts and analysed in an automated way or manually step by step. fig. 6 shows an example of the time charts with the coordinates of the characteristic points chosen by the user for analysis. The results can be printed as reports and saved as files in the comma separated value (CSV) format for further statistical analysis. The software runs on the Microsoft .Net Framework 4.0 platform and was prepared in the C\# language using the Visual Studio environment. Algorithms from specialized OpenCV and Luxand libraries were used to create the software.

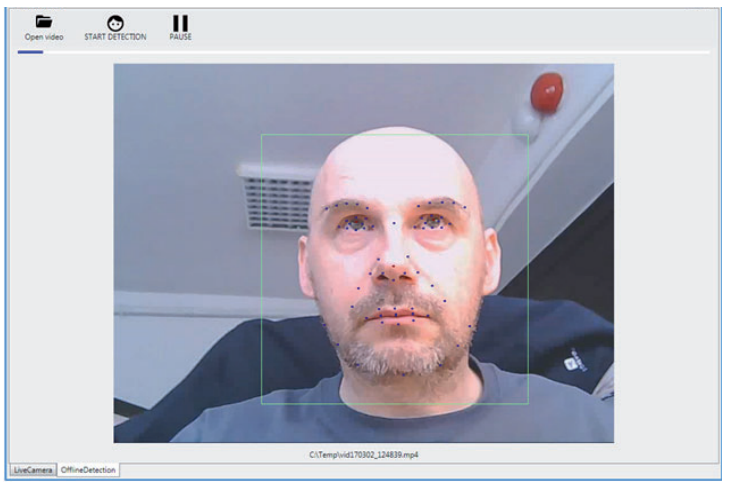

Fig. 5. Main panel of the software while detecting the characteristic points on the face.

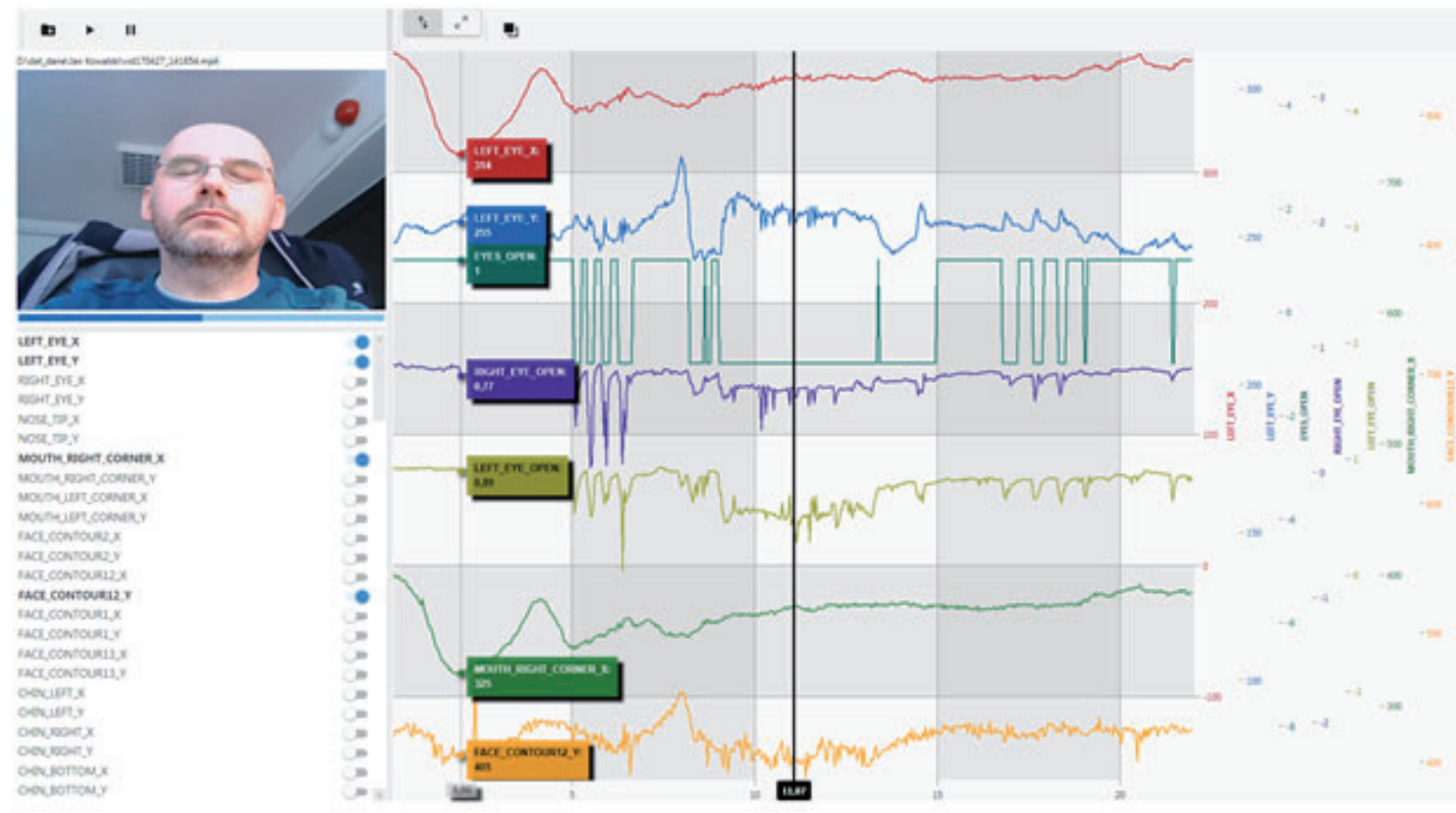

Fig. 6. Visualisation panel with the time charts chosen for analysis. 


\section{SUMMARY}

The location of the characteristic points is closely related to the arrangement of the eyes, eyebrows, nose, mouth and face oval. Their detection allows for calculating occulographic parameters and facial mimic-associated indicators, i.e.:

- eye opening/closing,

- PERCLOS calculated as the percentage of eyelid closure over the pupil in a pre-defined period of time; the simplified method of measuring the PERCLOS value is to calculate the ratio of the eyes being open and closed with the total number of frames for the given period $[15,17,24,31]$,

- ECD calculated as the number of closed eye frames divided by the number of eye closures in a pre-defined period of time $[11,24]$,

- FEC calculated as the number of eye closures in a pre-defined period of time [11,24],

- distance between the centres of the eyes and the corners of the mouth,

- eye surface area,

- yawning frequency.
The detector is a mobile device of a compact size, i.e. $61 \mathrm{~mm} \times 61 \mathrm{~mm} \times 66 \mathrm{~mm}$ in dimensions, and as low as $112 \mathrm{~g}$ in weight. It can be attached to the windscreen of any car or simulator. It does not limit visibility and in no way affects the safety of the driver. The detector can be used in studies to assess the occulographic parameters $[13,22,35]$ and facial-mimic reactions $[10,19,25,28]$ of drivers in response to various road situations, including unexpected events threatening traffic safety, e.g. sudden pedestrian intrusion on the road. The detector can be useful for assessing the behaviour and reaction of drivers during long-term and monotonous driving, which can cause weariness and drowsiness, e.g. driving on a highway. Moreover, the detector was developed for scientific experiments as it can not only deepen our knowledge about the effects of fatigue on drivers' psychophysical state and operational efficiency, but also allow for recording symptoms of weariness, drowsiness and fatigue appearing in drivers at their early stages. Finally, it is worth noting that due to its design, mobility, small size and the way of recording signals, the detector can be used not only for car drivers, but also for operators of other vehicles, e.g. rail vehicles.

\section{AUTHORS' DECLARATION:}

Study Design: Łukasz Dziuda, Krzysztof Murawski, Mariusz Dziwosz, Paulina Baran. Data Collection: Mariusz Dziwosz, Mariusz Krej, Marcin Piotrowski. Manuscript Preparation: Łukasz Dziuda, Paulina Baran. The Authors declare that there is no conflict of interest.

\section{REFERENCES}

1. Ahlstrom C, Nyström M, Holmqvist K, Fors C, Sandberg D, Anund A, et al. Fit-for duty test for estimation of drivers' sleepiness level: eye movements improve the sleep/wake predictor. Transp. Res. Part C Emerg. Technol. 2013; 26:20-32.

2. Applegate RA, Thibos LN, Twa MD, Sarver EJ. Importance of fixation, pupil center, and reference axis in ocular wavefront sensing, videokeratography, and retinal image quality. J. Cataract Refract. Surg. 2009; 35(1):139-152.

3. Bortkiewicz A. Zmęczenie w pracy kierowcy - przyczyny i skutki. In: Wągrowska-Koski E. (ed.), Zagrożenia zdrowia kierowców pojazdów silnikowych związane ze szkodliwymi i uciążliwymi warunkami środowiska pracy. 2007; 55-67. Łódź: Instytut Medycyny Pracy.

4. Caldwell JA, Caldwell JL, Brown DL, Smith JK. The effects of 37 hours of continuous wakefulness on the physiological arousal, cognitive performance, self-reported mood, and simulator flight performance of F-117A pilots. Military Psychology. 2004; 16:163-181.

5. De Gennaro L, Ferrara M, Curcio G, Bertini M. Visual search performance across 40h of continuous wakefulness: measures of speed and accuracy and relation with oculomotor performance. Physiology \& Behavior. 2001; 74:197-204. 
6. Di Stasi LL, Renner R, Catena A, Cañas JJ, Velichkovsky BM, Pannasch S. Towards a driver fatigue test based on the saccadic main sequence: a partial validation by subjective report data. Transp. Res. Part C Emerg. Technol. 2012; 21:122-133.

7. Di Stasi LL, McCamy MB, Pannasch S, Renner R, Catena A, Cañas JJ, et al. Effects of driving time on microsaccadic dynamics. Exp. Brain Res. 2015; 233(2):599-605.

8. Di Stasi LL, McCamy MB, Martínez-Conde S, et al. Effects of long and short simulated flights on the saccadic eye movement velocity of aviators. Physiology \& Behavior. 2016; 153:91-96.

9. Dong Y, Hu Z, Uchimura K. Driver inattention monitoring system for intelligent vehicles: a review. IEEE Trans. Intell. Transp. Syst. 2011; 12(2):596-614.

10. Donkor RA, Burnett GA, Sharples S. Measuring the emotional validity of driving simulators. Advances in Transportation Studies. 2014; 1:51-64.

11. D’Orazio T, Leo M, Guaragnella C, Distante A. A visual approach for driver inattention detection. Pattern Recognition. 2007; 40(8):2341-2355

12. Duque A, Sanchez A, Vazquez C. Gaze-fixation and pupil dilation in the processing of emotional faces: the role of rumination. Cog. Emotion. 2014; 28(8):1347-1366.

13. Hirvonen K, Puttonen S, Gould K, Korpela J, Koefoed VF, Muller K. Improving the saccade peak velocity measurement for detecting fatigue. Journal of Neuroscience Methods. 2010; 187(2):199-206.

14. Jagannath M, Balasubramanian V. Assessment of early onset of driver fatigue using multimodal fatigue measures in a static simulator. Applied Ergonomics. 2014; 45(4):1140-1147.

15. Jo J, Park KR, Kim I-J, Kim J. Detecting driver drowsiness using feature-level fusion and user-specific classification. Expert Systems with Applications. 2014; 41:1139-1152.

16. Li Z, Chen L, Peng J, Wu Y. Automatic detection of driver fatigue using driving operation information for transportation safety. Sensors. 2017; 17(6):1212.

17. Lin L, Huang C, Ni X, Wang J, Zhang H, Li X, Qian Z. Driver fatigue detection based on eye state. Technology and Health Care. 2015; 23:453-463.

18. Lohani M, Payne BR, Strayer DL. A review of psychophysiological measures to assess cognitive states in real-world driving. Frontiers in Human Neuroscience. 2019; 13, art. no. 57.

19. Lucas JL. Drivers' psychological and physical reactions after motor vehicle accidents. Transport Research Part F-Traffic Psychology and Behaiour. 2003; 6:135-145.

20. Meireles T, Dantas F. A low-cost prototype for driver fatique detection. Multimodal Technologies and Interaction. 2019; 3, art. no. 5.

21. Morales JM, Díaz-Piedra C, Rieiro H, Roca-González J, Romero S, Catena A, Fuentes L, Di Stasi LL. Monitoring driver fatigue using a single-channel electroencephalographic device: a validation study by gaze-based, driving performance, and subjective data. Accident Analysis \& Prevention. 2017; 109:62-69.

22. Rowland LM, Thomas ML, Thorne DR, Sing HC, Krichmar JL, Davis HQ, Balwinski SM, Peters RD, Kloeppel-Wagner E, Redmond DP, Alicandri E, Belenky G. Oculomotor responses during partial and total sleep deprivation. Aviation Space and Environmental Medicine. 2005; 76:C104-113.

23. Sahayadhas A, Sundaraj K, Murugappan M. Detecting driver drowsiness based on sensors: a review. Sensors. 2012; 12(12):16937-16953.

24. Schneider M, DemI B. An integrated approach of mental workload assessment. In Deml B, Stock P, Bruder R, Schlick CM ed: Advances in ergonomic design of systems, products and processes, Berlin Heidelberg; 2016:191-208.

25. Summala H. Towards understanding motivational and emotional factors in driver behaviour: Comfort through satisficing. Modelling driver behaviour in automotive environments. Springer. 2007.

26. Sundelin T, Lekander M, Kecklund G, Van Someren EJW, Olsson A, Axelsson J. Cues of fatigue: effects of sleep deprivation on facial appearance. Sleep. 2013; 36(9):1355-1360.

27. Ting PH, Hwang JR, Doong JL, Jeng MC. Driver fatigue and highway driving: a simulator study. Physiology and Behavior. 2008; 94(3):448-453.

28. Vaa T. Driver behavior models and monitoring of risk: Damasio and the role of emotions. International Conference: Traffic Safety on Three Continents. 2001; 10.

29. Vicente J, Laguna P, Bartra A, Bailón R. Drowsiness detection using heart rate variability. Medical \& Biological Engineering \& Computing. 2016; 54(6):927-937.

30. Wang H, Dragomir A, Abbasi NI, Li J, Thakor NV, Bezerianos A. A novel real-time driving fatigue detection system based on wireless dry EEG. Cognitive Neurodynamics. 2018; 12(4):365-376. 
Dziuda $Ł$. et al. - Construction of a detector ...

31. Wierwille WW, Wreggit SS, Kirn CL, Ellsworth LA, Fairbanks RJ (1994). Research on vehicle-based driver status/performance monitoring; development, validation, and refinement of algorithms for detection of driver drowsiness. Final Report. National Highway Traffic Safety Administration. 1994.

32. Williamson A, Lombardi DA, Folkard S, Stutts J, Courtney TK, Connor JL. The link between fatigue and safety. Accident Analysis and Prevention. 2011; 432:498-515.

33. Xu J, Min J, Hu J. Real-time eye tracking for the assessment of driver fatigue. Healthcare Technology Letters. 2018; 5(2):54-58.

34. Yu-Lung C, Yen-Cheng F, Chen OT. Real-time physiological and facial monitoring for safe driving. Conf Proc IEEE Eng Med Biol Soc. 2016; 4849-4852. doi: 10.1109/EMBC.2016.7591813.

35. Zils E, Sprenger A, Heide W, Born J, Gais S. Differential effects of sleep deprivation on saccadic eye movements. Sleep. 2005; 28:1109-1115.

Cite this article as: Dziuda $\measuredangle$, Murawski K, Dziwosz M, Krej M, Piotrowski M, Baran P. Construction Of A Detector Of Fatigue Symptoms In Car Drivers. Pol J Aviat Med Bioeng Psychol 2018; 24(3): 23-29. DOI: 10.13174/pjambp. 11.02.2020.04 